\title{
Deformation Forecast of Main Girder Enhanced by Stay Cable System with Unequal Interval Grey Model and Residual Composite Correction
}

\author{
Gangnian Xu $(\mathbb{D}$, Youzhi Wang $(\mathbb{D}$, Shimin Wang, and Quan Yuan \\ School of Civil Engineering, Shandong University, Jinan 250061, China \\ Correspondence should be addressed to Youzhi Wang; wangyouzhi@sdu.edu.cn
}

Received 16 February 2018; Revised 9 May 2018; Accepted 29 May 2018; Published 21 June 2018

Academic Editor: Roman Wan-Wendner

Copyright (C) 2018 Gangnian Xu et al. This is an open access article distributed under the Creative Commons Attribution License, which permits unrestricted use, distribution, and reproduction in any medium, provided the original work is properly cited.

\begin{abstract}
This paper aims to achieve the accurate prediction of box girder deformation in SCS-enhanced PSC continuous box girder bridges. To this end, the authors proposed a box girder deformation prediction model based on unequal interval grey model (UIGM) and residual composite correction (RCC). Firstly, the tension forces of cables and the deformation data of box girder were regarded as the time sequence and the original unequal interval sequence, respectively, and the UIGM was constructed to predict the box girder deformation. Secondly, the sine function was constructed on the average features of the residual sequence waveform, and the periodic sequence function was generated by harmonic transform. The two functions were employed to extract the implicit periodic information and overcome the limitation of the UIGM (i.e., the UIGM only generates the change rate of a single index). Finally, the Markov chain method was adopted to treat the random fluctuations and further enhance the prediction accuracy and adaptability of the model. Then, the proposed UIGM-RCC was applied to predict the box girder deformation of Dongming Huanghe River Highway Bridge and forecast the settlement of a building mentioned in previous research. The results show that the proposed model can reflect the exact periodicity and random fluctuations of box girder deformation in SCS-enhanced PSC continuous box girder bridges. The research findings provide a meaningful reference for improving deformation prediction accuracy in SCS-enhanced structures.
\end{abstract}

\section{Introduction}

Prestressed-concrete (PSC) continuous box girder bridges often suffer from midspan lag and box girder cracking $[1,2]$. These problems can be resolved by enhancing the bridges with a stay cable system (SCS) [3]. However, it is immensely difficult to predict the deformation of the SCS-enhanced box girder because of the fuzzy, stochastic, and indeterminant mechanical form and deformation mechanism of the bridges under natural and anthropic factors [4]. Considering the limits of existing theories and methods, the most practical way to elevate prediction accuracy lies in the estimation of girder deformation based on monitoring data [5-7].

In view of the indeterminacy, poor information, and high cost of sample data, many scholars have successfully introduced the grey system theory to solve engineering problems [8-10]. Nevertheless, the common grey prediction model only applies to strictly equal interval sequences, adding to the difficulty of engineering application. Taking the SCS as an example, the cable force control often relies on the force difference of unequal interval cables, with the aim to make tensioning more flexible. Moreover, the grey system theory may have low prediction accuracy and increased error, owing to the weak periodicity and strong random fluctuations of the box girder's deformation sequence [11].

Based on the box girder deformation data of an SCSenhanced PSC continuous box girder bridge, this paper discloses the relationship between the deformation pattern and the grey theory and proposes a deformation prediction model combining the unequal interval grey model (UIGM) and the residual composite correction (RCC). On one hand, the UIGM was adopted to solve the indeterminacy, poor information, and high cost of the sample data. On the other hand, the RCC was employed to enhance the low accuracy of the UIGM and the adaptability of the whole prediction model. Specifically, the sine function was constructed on 
the average features of the residual sequence waveform; the periodic sequence function was generated by harmonic transform. The two functions were employed to correct the residual sequence, which is random and alternatively positive and negative. Finally, the prediction results were compared with the data of the previous research. The comparison shows that the proposed prediction model has high accuracy and strong adaptability. This research provides a new control method for box girder deformation on SCS-enhanced bridges and boasts great theoretical and practical potential.

\section{The Building and Solving of Unequal Interval Grey Model}

Based on unequal interval grey theory [13], the cable force in tensioning phase was regarded as the original time sequence, and the vertical deformation of box girder recorded at the measuring points was deemed as the original unequal interval sequence. Then, the authors created the deformation prediction model of SCS-enhanced box girder in tensioning phase. The monitoring data on box girder deformation were processed by the sequential operators to disclose the change pattern, generate data sequences with certain regularity, and establish the corresponding differential equation, laying the basis for quantitative prediction of change.

2.1. Deformation Prediction Model of SCS-Enhanced Box Girder. Suppose the original sequence of box girder deformation is

$$
\begin{aligned}
& X^{(0)} \\
& \quad=\left(X^{(0)}\left(F_{1}\right), X^{(0)}\left(F_{2}\right), \cdots, X^{(0)}\left(F_{k}\right), \cdots, X^{(0)}\left(F_{n}\right)\right)
\end{aligned}
$$

If the cable force difference between the $k$ th and the $k-1$ th tensioning phases is $\Delta F_{k}$, then

$$
\Delta F_{k}=F_{k}-F_{k-1} \neq \text { const }, \quad k=2,3, \cdots, n
$$

where $\Delta F_{1}=1$.

Therefore, a one-time accumulated generation formula of the original sequence is

$$
\begin{aligned}
& X^{(1)}\left(F_{1}\right)=X^{(0)}\left(F_{1}\right) \\
& X^{(1)}\left(F_{k}\right)=X^{(1)}\left(F_{k-1}\right)+\Delta F_{k} X^{(0)}\left(F_{k}\right),
\end{aligned}
$$

$$
k=2,3, \cdots, n
$$

According to formula (3), formula (1) can be rewritten as an unequal interval time-varying monotonically increasing sequence $X^{(1)}$ :

$$
\begin{aligned}
& X^{(1)} \\
& \quad=\left(X^{(1)}\left(F_{1}\right), X^{(1)}\left(F_{2}\right), \cdots, X^{(1)}\left(F_{k}\right), \cdots, X^{(1)}\left(F_{n}\right)\right)
\end{aligned}
$$

Then, the differential equation of grey model can be established by the first-order generation module $X^{(1)}$ :

$$
\frac{d X^{(1)}}{d F}+a X^{(1)}=u
$$

where $a$ is the developing coefficient; $u$ is the grey activity.

The solution to the differential equation of the unequal interval sequence is

$$
\widehat{X}^{(1)}\left(F_{k}\right)=\left[X^{(1)}\left(F_{1}\right)-\frac{u}{a}\right] e^{-a\left(F_{k}-F_{1}\right)}+\frac{u}{a}
$$

Since $X^{(1)}\left(F_{1}\right)$ and $a$ and $u$ are constants, if $q=X^{(1)}\left(F_{1}\right)-u / a$, then formula (6) can be transformed into

$$
\widehat{X}^{(1)}\left(F_{k}\right)=q\left[e^{-a\left(F_{k}-F_{1}\right)}-1\right]+X^{(1)}\left(F_{1}\right)
$$

According to formula (3), perform a cumulative reduction and the fitting value can be obtained as

$$
\begin{aligned}
& \widehat{X}^{(0)}\left(F_{1}\right)=\widehat{X}^{(1)}\left(F_{1}\right) \\
& \widehat{X}^{(0)}\left(F_{k}\right)=\frac{\widehat{X}^{(1)}\left(F_{k}\right)-\widehat{X}^{(1)}\left(F_{k-1}\right)}{\Delta F_{k}}, \quad k=2,3, \cdots, n
\end{aligned}
$$

2.2. Solution to Grey Parameters. To make the fitting value $\widehat{X}^{(1)}\left(F_{k}\right)$ infinitely close to the original value $X^{(1)}\left(F_{k}\right)$, the grey parameters $a$ and $q$ were solved by the relationship between the fitting value and the accumulated data:

$$
\begin{gathered}
X^{(1)}\left(F_{2}\right)=\widehat{X}^{(1)}\left(F_{2}\right)=q\left[e^{-a\left(F_{2}-F_{1}\right)}-1\right]+X^{(1)}\left(F_{1}\right) \\
X^{(1)}\left(F_{3}\right)=\widehat{X}^{(1)}\left(F_{3}\right)=q\left[e^{-a\left(F_{3}-F_{1}\right)}-1\right]+X^{(1)}\left(F_{1}\right) \\
\vdots \\
X^{(1)}\left(F_{n}\right)=\widehat{X}^{(1)}\left(F_{n}\right)=q\left[e^{-a\left(F_{n}-F_{1}\right)}-1\right]+X^{(1)}\left(F_{1}\right)
\end{gathered}
$$

The grey parameters $a$ and $q$ are both constants. Formula (9) contains $n-1$ equations; any two of these equations could be constructed as simultaneous equation. For example, the $i$ th and $j$ th equations are constructed as follows:

$$
\begin{aligned}
& X^{(1)}\left(F_{i}\right)=q\left[e^{-a\left(F_{i}-F_{1}\right)}-1\right]+X^{(1)}\left(F_{1}\right) \\
& X^{(1)}\left(F_{j}\right)=q\left[e^{-a\left(F_{j}-F_{1}\right)}-1\right]+X^{(1)}\left(F_{1}\right)
\end{aligned}
$$

Solving (10), the value of grey parameter can be gotten and denoted as $a_{i j}$; then

$$
a_{i j}=\frac{1}{F_{j}-F_{i}} \ln \left[\frac{F_{j}-F_{1}}{F_{i}-F_{1}} \cdot \frac{X^{(1)}\left(F_{i}\right)-X^{(1)}\left(F_{1}\right)}{X^{(1)}\left(F_{j}\right)-X^{(1)}\left(F_{1}\right)}\right]
$$

where $a_{i j}$ represents the grey parameter value obtained by the $i$ th and $j$ th equations.

Construct simultaneous equation by any two equations in formula (9); $(n-1)(n-2) / 2$ grey parameters could be solved out and the average value of them is 


$$
\begin{aligned}
\bar{a} & =\frac{2}{(n-1)(n-2)} \sum_{i=2}^{n-1} \sum_{j=i+1}^{n} a_{i j} \\
& =\frac{2}{(n-1)(n-2)} \sum_{i=2}^{n-1} \sum_{j=i+1}^{n}\left\{\frac{\ln \left[\left(\left(F_{j}-F_{1}\right) /\left(F_{i}-F_{1}\right)\right) \cdot\left(\left(X^{(1)}\left(F_{i}\right)-X^{(1)}\left(F_{1}\right)\right) /\left(X^{(1)}\left(F_{j}\right)-X^{(1)}\left(F_{1}\right)\right)\right)\right]}{F_{j}-F_{i}}\right\}
\end{aligned}
$$

Literature [14] takes the average value $\bar{a}$ as the final grey parameter $a$ of the model and substitutes it into (9); then $q_{i}$ can be gotten, and the average value of them is

$$
\bar{q}=\frac{1}{n-1} \sum_{i=2}^{n} q_{i}=\frac{1}{n-1} \sum_{i=2}^{n}\left[\frac{X^{(1)}\left(F_{i}\right)-X^{(1)}\left(F_{1}\right)}{e^{-a\left(F_{i}-F_{1}\right)}-1}\right]
$$

where $q_{i}$ presents the grey parameter obtained by the $i$ th equation.

Take $\bar{q}$ as the final grey parameter $q$ of the model, substitute $a$ and $q$ into formula (7), and perform inverse accumulated generating operation (IAGO). The resultant fitting value $\widehat{X}^{(0)}\left(F_{k}\right)$ of the original sequence is

$$
\begin{aligned}
& \widehat{X}^{(0)}\left(F_{1}\right)=X^{(1)}\left(F_{1}\right) \\
& \widehat{X}^{(0)}\left(F_{k}\right)=\frac{q\left(e^{-a F_{k}}-e^{-a F_{k-1}}\right)}{e^{-a F_{1}} \Delta F_{k}}, \quad k=2,3, \cdots, n
\end{aligned}
$$

Then, the prediction value in the next tension stage is

$$
\begin{aligned}
\widehat{X}^{(0)}\left(F_{k+1}\right) & =\frac{\widehat{X}^{(1)}\left(F_{k+1}\right)-\widehat{X}^{(1)}\left(F_{k}\right)}{\Delta F_{k+1}} \\
& =\frac{q\left(e^{-a F_{k+1}}-e^{-a F_{k}}\right)}{e^{-a F_{1}} \Delta F_{k+1}}
\end{aligned}
$$

\section{The Residual Composite Correction (RCC)}

3.1. The Sine and the Periodic Sequence Function Residual Correction (SPSFRC). After the girder deformation trend was fitted and predicted by the UIGM, the residual sequence was alternatively positive and negative, showing an unobvious periodicity. For better fitting and prediction accuracy, the sine function, constructed on the average features of the residual sequence waveform, and the periodic sequence function, generated by harmonic transform, were employed to modify the residual sequence [15]. The two functions are collectively referred to as the SPSFRC. Coupled with the UIGM, the SPSFRC can extract the implicit periodic information and overcome the limitation of the UIGM (i.e., the UIGM only generates the change rate of a single index). The SPSFRC is established in the following steps.

Step 1. Build the residual sequence $E^{(0)}\left(F_{k}\right)$.

$$
E^{(0)}\left(F_{k}\right)=X^{(0)}\left(F_{k}\right)-\widehat{X}^{(0)}\left(F_{k}\right), \quad k=1,2, \cdots, n
$$

Step 2. Fit $E^{(0)}\left(F_{k}\right)$ by sine function $\widehat{E} 1^{(0)}\left(F_{k}\right)$, constructed on the average features of the residual sequence waveform.

$$
\widehat{E} 1^{(0)}\left(F_{k}\right)=A \sin \frac{2 \pi\left(F_{k}+T / 2\right)}{T}
$$

where $A=(1 / n) \sum_{i=1}^{n}\left|E^{(0)}\left(F_{k}\right)\right| ; T$ is the average value of residual sequence $E^{(0)}\left(F_{k}\right)$ wave time span; its optimal value follows the principle of the minimum quadratic sum $e 1_{\min }$ of the fitting values residual for sine function; that is, $e 1_{\min }=$ $\min \left\{e 1_{1}, e 1_{2}, \cdots, e 1_{i}, \cdots, e 1_{n}\right\}$ and $e 1_{i}=\sum_{k=1}^{n}\left[E 1^{(0)}\left(F_{k}\right)-\right.$ $\left.\widehat{E} 1_{i}^{(0)}\left(F_{k}\right)\right]^{2}$.

Step 3. Fit $E^{(0)}\left(F_{k}\right)$ by periodic sequence function $\widehat{E} 2^{(0)}\left(F_{k}\right)$ generated by harmonic variation:

$$
\widehat{E} 2^{(0)}\left(F_{k}\right)=a_{0}+\sum_{i=1}^{m}\left[a_{i} \cos \left(\omega_{i} F_{k}\right)+b_{i} \sin \left(\omega_{i} F_{k}\right)\right]
$$

where $\omega_{i}=2 i \pi / F_{n}, i=1,2, \cdots, m, a_{0}=$ $(1 / n) \sum_{k=1}^{n} E^{(0)}\left(F_{k}\right), a_{i}=(2 / n) \sum_{k=1}^{n} E^{(0)}\left(F_{k}\right) \cos \left(\omega_{i} F_{k}\right), b_{i}=$ $(2 / n) \sum_{k=1}^{n} E^{(0)}\left(F_{k}\right) \sin \left(\omega_{i} F_{k}\right)$.

Step 4. Introduce the weight coefficient $\xi(0 \leq \xi \leq 1)$ to combine the weights with formulas (17) and (18) and obtain the residual fitting value $\widehat{E}^{(0)}\left(F_{k}\right)$.

$$
\begin{aligned}
& \widehat{E}^{(0)}\left(F_{1}\right)=E^{(0)}\left(F_{1}\right) \\
& \widehat{E}^{(0)}\left(F_{k}\right)=(1-\xi) \widehat{E} 1\left(F_{k}\right)+\xi \widehat{E} 2\left(F_{k}\right),
\end{aligned}
$$

$$
k=2,3, \cdots, n
$$

Also, the optimal value of $\xi$ and $m$ follows the principle of the minimum quadratic sum $e 2_{\text {min }}$ of the fitting values residual by SPSFRC; that is, $e 2_{\min }=\min \left\{e 2_{1}, e 2_{2}, \cdots, e 2_{i}, \cdots, e 2_{n}\right\}$ and $e 2_{i}=\sum_{k=1}^{n}\left[E^{(0)}\left(F_{k}\right)-\widehat{E}_{i}^{(0)}\left(F_{k}\right)\right]^{2}$.

Step 5. Calculate the prediction value modified by the SPSFRC.

$$
\begin{aligned}
& \widehat{X}_{1}^{(0)}\left(F_{1}\right)=\widehat{X}^{(0)}\left(F_{1}\right) \\
& \widehat{X}_{1}^{(0)}\left(F_{k}\right)=\widehat{X}^{(0)}\left(F_{k}\right)+\widehat{E}^{(0)}\left(F_{k}\right), \quad k=2,3, \cdots, n
\end{aligned}
$$

The box girder deformation of the $k+1$ th tensioning phase can be predicted based on the data of the previous $k$ tensioning phases. Then, the residual composite correction value of the $F_{k+1}$ tensioning phase is $\widehat{X}_{1}^{(0)}\left(F_{k+1}\right)$. 
3.2. Markov Chain Residual Correction. The prediction based on the Markov chain [16] mainly derives the possible future state of a system based on the current state and the change trend of system variables. This approach is particularly suitable for problems with strong randomness. Under the influence of various factors, the box girder deformation has a stochastic growth rate and growth probability. Therefore, the Markov chain-based prediction can enhance the random features of the box girder deformation sequence and improve the prediction results. Suppose that the random system $X$ is in state $i_{n}$ at time $t$. Then, its state at time $t+1$ has nothing to do with the state before time $t$ :

$$
P\left\{X_{n+1}=i_{n+1} \mid X_{0}=i_{0}, X_{1}=i_{1}, \cdots, X_{n}=i_{n}\right\}
$$

The actual sequence is rationally divided into several states $S_{1}, S_{2}, \cdots, S_{n}$. Then, the state transition probability at step $f$ is

$$
P_{i k}^{(f)}=\frac{N_{i k}^{(f)}}{\sum_{k=1}^{n} N_{i k}^{(f)}}
$$

where $N_{i k}^{(f)}$ is the number of states transferred from $S_{i}$ to $S_{k}$ by $f$ steps in the system sequence; $\sum_{k=1}^{n} N_{i k}^{(f)}$ is the amount of raw data in state $S_{i}$ of the sequence.

Define the state transition matrix at step $f$ as

$$
P^{(f)}=\left[\begin{array}{cccc}
P_{11}^{(f)} & P_{12}^{(f)} & \cdots & P_{1 n}^{(f)} \\
P_{21}^{(f)} & P_{22}^{(f)} & \cdots & P_{2 n}^{(f)} \\
\vdots & \vdots & & \vdots \\
P_{n 1}^{(f)} & P_{n 2}^{(f)} & \cdots & P_{n n}^{(f)}
\end{array}\right]
$$

where $\sum_{k=1}^{n} P_{i k}^{(f)}=1$.

The division of the state interval is generally combined with the mean value and standard deviation of the data sequence [17]. The centre of each interval, that is, the average value of the two endpoints, is recorded as the state centre $\chi_{i}$. For Markov chain-based residual prediction, the residual sequence $E^{(0)}\left(F_{k}\right)$ was divided into $n$ states $S$. $r$ transition probability vectors (the rows of a matrix) are needed to consider the transition processes in $r$ steps. The probability of residual state at the target moment is the sum of the $r$ vectors. The elements of each vector are denoted as $\eta_{1}, \eta_{2}, \cdots, \eta_{n}$. If there are a total of $n$ intervals of state $S$, then the residual correction prediction value of the target moment, that is, the next moment, is

$$
\begin{aligned}
M\left(F_{k+1}\right) & =\lambda_{1} \chi_{1}+\lambda_{2} \chi_{2}+\cdots+\lambda_{n} \chi_{n} \\
\lambda_{i} & =\frac{\eta_{i}}{\eta_{1}+\eta_{2}+\cdots+\eta_{n}}
\end{aligned}
$$

where $\lambda_{i}$ is the state weight; $\chi_{i}$ is the state interval centre.

After Markov chain-based prediction, the prediction value of the UIGM-RCC is corrected as

$$
\widehat{X}_{2}^{(0)}\left(F_{k+1}\right)=\widehat{X}_{1}^{(0)}\left(F_{k+1}\right)+M\left(F_{k+1}\right)
$$

TABLE 1: The deformation values of C21 in different tensioning phases.

\begin{tabular}{lcc}
\hline Tensioning phase & Tensioning force $/ \mathrm{kN}$ & Deformation $/ \mathrm{mm}$ \\
\hline 1 & 630 & 25.30 \\
2 & 1,050 & 31.33 \\
3 & 1,155 & 33.27 \\
4 & 1,365 & 37.15 \\
5 & 1,575 & 42.78 \\
6 & 1,785 & 45.18 \\
7 & 1,890 & 47.23 \\
\hline
\end{tabular}

\section{Case Study}

4.1. Overview. The main bridge of Dongming Huanghe River Highway Bridge is a PSC continuous box girder bridge. The $990 \mathrm{~m}$ long bridge has a total of nine spans within the lengths: 75m-120m-120m-120m-120m-120m-120m-120m-75m. To overcome girder cracking and midspan sag, the main bridge was reinforced by the SCS, marking the first project of its kind in China. The bridge towers, the main beam, and the cables are connected as follows. The cables are fixed onto the top of bridge towers via steel anchor boxes and sliding cable saddles. The trimmer beams, laid laterally beneath the box girder, are attached to the bottom of the box girder by base plate [3]. The force on the stay cables is transmitted to the main beam through the trimmer beams and base plates. The designed force of long cable is $2,700 \mathrm{kN}$ and that of short cable is $2,100 \mathrm{kN}$. During the construction, the cables were tensioned symmetrically by 8 lifting jacks. Thus, the cables become shorter and shorter from the middle towers (61\# and 62\#) to the side towers (58\# and 65\#). To capture the box girder deformation during the tensioning, 114 vertical displacement measuring points were placed upstream and downstream of the bridge. In the actual project, the cable tensioning phases are divided into 7 stages, and the final tension values of long and short cables are $90 \%$ of the design cable values of the bridge, which are $2,430 \mathrm{kN}$ and $1,890 \mathrm{kN}$, respectively. This paper elaborates and studies according to the tension force values of short cables, namely, $630 \mathrm{kN}, 1,050$ $\mathrm{kN}, 1,155 \mathrm{kN}, 1,365 \mathrm{kN}, 1,575 \mathrm{kN}, 1,785 \mathrm{kN}$, and 1,890 kN. The drawing of Dongming Huanghe River Highway Bridge strengthened by the stay cable system is shown in Figure 1.

4.2. Example Analyzing. To verify the performance of the proposed prediction model, the deformation values of the box girder at C21 measuring point in the 1st 7 th tensioning phases were selected for modelling analysis (Table 1). The values of the first 6 tensioning phases were taken as the raw data, and the deformation value of the 7 th tensioning phase was considered as the target of prediction.

(1) The fitting values $\widehat{X}^{(0)}\left(F_{k}\right)$ and preliminary prediction values $\widehat{X}^{(0)}\left(F_{k+1}\right)$ were obtained by the UIGM, and then the residual sequence $E^{(0)}\left(F_{k}\right)$ of the fitting values was figured out.

Table 2 contains the fitting values of the first 6 tensioning phases. It can be seen that the UIGM has a large error in fitting, but the error is gradually decreasing. For the 7 th 


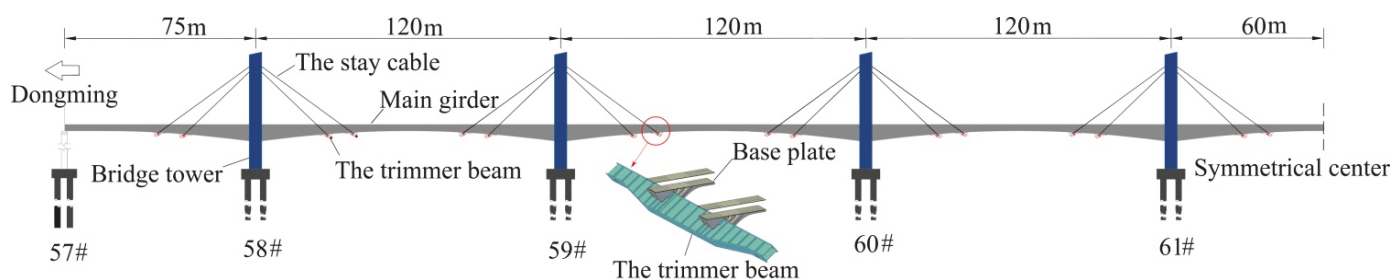

FIGURE 1: Drawing of Dongming Huanghe River Highway Bridge strengthened by the stay cable system.

TABLE 2: The fitting values by UIGM.

\begin{tabular}{lcccc}
\hline Tensioning force $/ \mathrm{kN}$ & Measured values/mm & Fitting values $/ \mathrm{mm}$ & Residual/mm & Relative error/\% \\
\hline 630 & 25.30 & 25.3000 & 0.0000 & 0.0000 \\
1,050 & 31.33 & 32.4076 & -1.0776 & -3.4395 \\
1,155 & 33.27 & 34.4138 & -1.1438 & -3.4379 \\
1,365 & 37.15 & 35.6871 & 1.4629 & 3.9378 \\
1,575 & 42.78 & 37.4548 & 5.3252 & 12.4479 \\
1,785 & 45.18 & 39.3101 & 5.8699 & 12.9923 \\
\hline
\end{tabular}

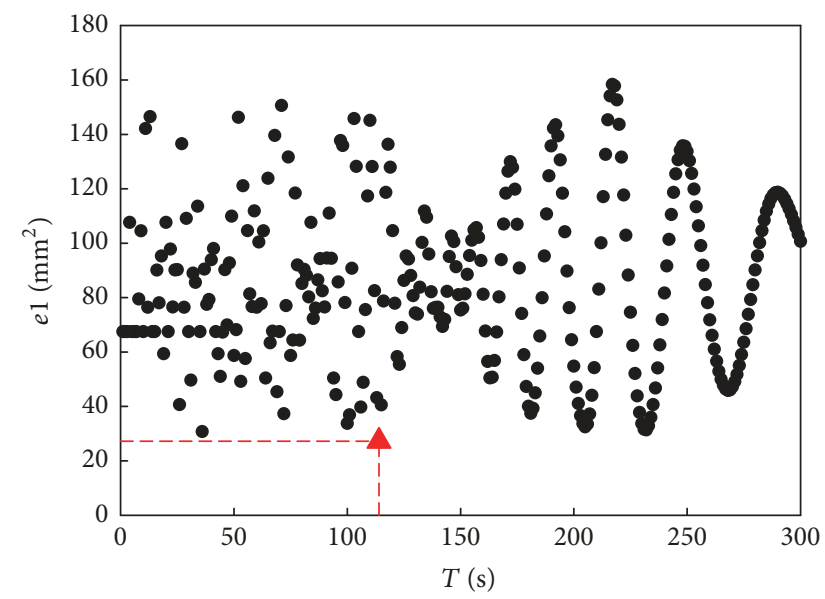

FIGURE 2: Relationship between parameter $T$ and quadratic sum $e 1$ of the fitting values.

tensioning phase, the predicted value of UIGM is $40.7586 \mathrm{~mm}$, which is quite different from measuring value, and the relative error is $13.7019 \%$.

(2) Calculate the optimal composite parameters of the SPSFRC, the fitting values of the residual sequence, and the prediction values $\widehat{X}_{1}^{(0)}\left(F_{k+1}\right)$ after one correction.

First, the sine function was used to modify $E^{(0)}\left(F_{k}\right)$, and the optimal parameter $T_{\text {best }}$ was determined by the quadratic sum $e 1$ of the fitting values. Let $T \in[1,10,000]$ and let the step length be 1 . The optimal result $e 1_{\text {min }}=27.2228 \mathrm{~mm}^{2}$ was obtained at $T=114 \mathrm{~s}$. Figure 2 shows the results of the first 300 iterations. In Figure 2, the triangle represents the corresponding point of the optimal result.

After that, the residual sequence was modified by the periodic sequence function and sine function generated by harmonic transform. The optimal parameters $\xi_{\text {best }}$ and $m_{\text {best }}$ were still determined by the quadratic sum $e 2$ of the fitting values. Suppose that $\xi \in[0,1]$ with a step length of 0.01

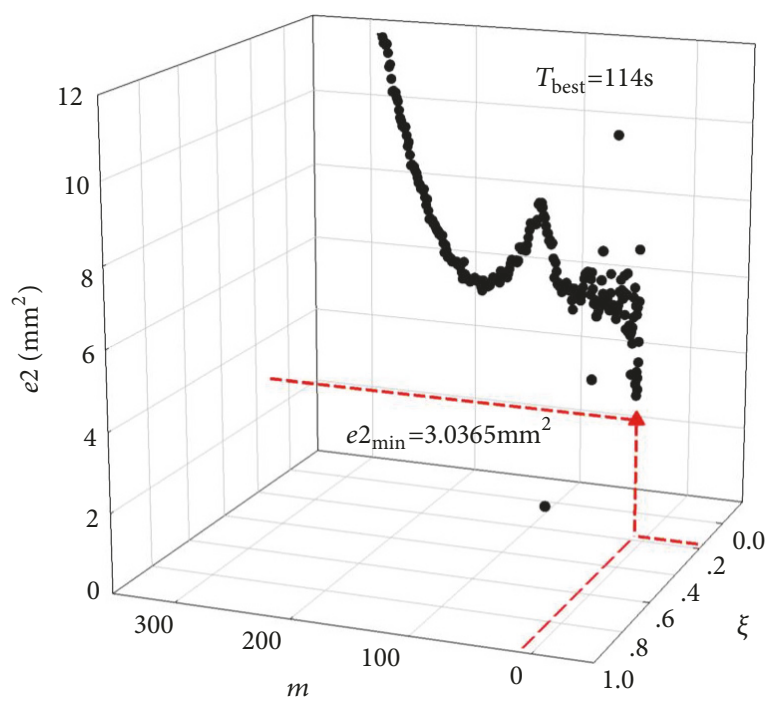

FIGURE 3: Relationship between parameters $\xi$ and $m$ and quadratic sum $e 2$ of the fitting values at $T_{\text {best }}=114 \mathrm{~s}$.

and $m \in[1,10,000]$ with a step length of 1 . In this case, the cumulative residual of the fitting values was minimal $\left(e 2_{\min }=\right.$ $3.0365 \mathrm{~mm}^{2}$ ) at $T=114 \mathrm{~s}, \xi=0.17$, and $m=10$. Figure 3 shows the results of the first 300 iterations. In Figure 3, the triangle represents the corresponding point of the optimal result.

There are 6 pieces of data in the residual sequence of the first 6 tensioning phases. The fitting values modified by the SPSFRC are

$$
\begin{aligned}
& \widehat{E}^{(0)}\left(F_{k}\right)=\left(\widehat{E}^{(0)}\left(F_{1}\right), \widehat{E}^{(0)}\left(F_{2}\right), \widehat{E}^{(0)}\left(F_{3}\right), \widehat{E}^{(0)}\left(F_{4}\right)\right. \\
& \left.\widehat{E}^{(0)}\left(F_{5}\right), \widehat{E}^{(0)}\left(F_{6}\right)\right)=(0.0000,-2.3696 \\
& -2.2550,1.5893,5.5899,5.6544)
\end{aligned}
$$


TABLE 3: States of residual sequence.

\begin{tabular}{lcc}
\hline Tensioning force/kN & Residual & State \\
\hline 630 & 0.0000 & $S_{1}$ \\
1,050 & -1.7078 & $S_{1}$ \\
1,155 & -1.1438 & $S_{1}$ \\
1,365 & 1.4629 & $S_{2}$ \\
1,575 & 5.3252 & $S_{3}$ \\
1,785 & 5.8699 & $S_{3}$ \\
\hline
\end{tabular}

The 7th tensioning phase, that is, $1,890 \mathrm{kN}$, was substituted into the SPSFRC, putting the correction value at 1.0441. Thus, the prediction value after one correction is

$$
\begin{aligned}
\widehat{X}_{1}^{(0)}\left(F_{7}\right) & =\widehat{X}^{(0)}\left(F_{7}\right)+\widehat{E}^{(0)}\left(F_{7}\right)=40.7586+1.0441 \\
& =41.8027
\end{aligned}
$$

The above analysis shows that the SPSFRC improved the prediction accuracy by lowering the relative error to $11.49 \%$.

(3) Divide the residual sequence into different state intervals according to the Markov chain, solve the state transition matrix $P^{(f)}$ of the residual sequence, and figure out the Markov residual prediction value $M\left(F_{k+1}\right)$ and the final prediction value $\widehat{X}_{2}^{(0)}\left(F_{k+1}\right)$.

The residual sequence was divided into 3 state intervals based on the mean value $\mu$ and standard deviation $\sigma$ of the residual sequence: $[\mu-1.9 \sigma, \mu-0.6 \sigma],[\mu-0.6 \sigma, \mu+0.6 \sigma]$, and $[\mu+0.6 \sigma, \mu+1.9 \sigma]$, corresponding to states $S_{1}, S_{2}$, and $S_{3}$. These states should cover the entire range of the residual sequence. The range of the 3 states is $[-3.71,0.02],[0.02,3.46]$, and $[3.46,7.18]$, respectively. The corresponding states are shown in Table 3.

$$
\begin{aligned}
& P^{(1)}=\left[\begin{array}{lll}
\frac{2}{3} & \frac{1}{3} & 0 \\
0 & 0 & 0 \\
0 & 0 & 1
\end{array}\right], \\
& P^{(2)}=\left[\begin{array}{lll}
\frac{1}{3} & \frac{1}{3} & \frac{1}{3} \\
0 & 0 & 1 \\
0 & 0 & 0
\end{array}\right], \\
& P^{(3)}=\left[\begin{array}{lll}
0 & \frac{1}{3} & \frac{2}{3} \\
0 & 0 & 0 \\
0 & 0 & 0
\end{array}\right] .
\end{aligned}
$$

The residual value of the 7 th tensioning phase was predicted based on the transitions of the first 6 tensioning phases. The transition contains a total of 3 steps, and the transition probabilities are listed in Table 4 .

Solved by $\eta$, the state weights are $\lambda_{1}=\lambda_{2}=0$ and $\lambda_{3}=1$, and the state centres are $\chi_{1}=-1.8425, \chi_{2}=1.7394$,
TABLE 4: State transition probabilities.

\begin{tabular}{lcccc}
\hline \multirow{2}{*}{ Transition step } & \multirow{2}{*}{ State } & \multicolumn{3}{c}{ Transition probability } \\
& & $S_{1}$ & $S_{2}$ & $S_{3}$ \\
\hline $1(1,785 \mathrm{kN})$ & $S_{3}$ & 0 & 0 & 1 \\
$2(1,575 \mathrm{kN})$ & $S_{3}$ & 0 & 0 & 0 \\
$3(1,365 \mathrm{kN})$ & $S_{2}$ & 0 & 0 & 0 \\
\hline \multicolumn{2}{c}{ Total probability $\lambda$} & 0 & 0 & 1 \\
\hline
\end{tabular}

and $\chi_{3}=5.3214$. Then, the Markov chain-based residual prediction value of the 7 th tensioning phase is

$$
\begin{aligned}
M\left(F_{7}\right) & =\lambda_{1} \cdot \chi_{1}+\lambda_{2} \cdot \chi_{2}+\lambda_{3} \cdot \chi_{3} \\
& =0 \times(-1.8425)+0 \times 1.7394+1 \times 5.3214 \\
& =5.3214
\end{aligned}
$$

Thus, the final deformation of the box girder of the 7 th tensioning phase is

$$
\begin{aligned}
\widehat{X}_{2}^{(0)}\left(F_{7}\right) & =\widehat{X}_{1}^{(0)}\left(F_{7}\right)+M\left(F_{7}\right)=41.8027+5.3214 \\
& =47.1241
\end{aligned}
$$

The fitting accuracy of the proposed UIGM-RCC was compared with the UIGM model and the measured values (Table 5). It is clear that the proposed model outshines the UIGM model in fitting accuracy. It can be seen from the prediction result of the 7 th deformation value that the relative errors of UIGM-RCC and UIGM are $0.2243 \%$ and $13.7019 \%$, respectively. The results show that the fitting and predicted values of the proposed model in this paper are close to the measuring values.

In the same way, the deformation values of the 8th 12th times (i.e., 2,100 kN, 2,205 kN, 2,310 kN, 2,415 kN, and $2,520 \mathrm{kN}$ tension forces) are extrapolated. Table 6 contains the prediction values obtained by UIGM and UIGM-RCC. For intuitiveness, the data in Tables 5 and 6 were converted into graphs (Figure 4).

For further verification of the fitting effect, prediction accuracy, and adaptability, the box girder deformation values of other measuring points in the first 6 tensioning phases were selected as the original data (Table 7) to predict the deformation in the 7 th tensioning phase. $L$ denotes distance from center line of 57 \# pier in Table 7.

The optimal parameter values and prediction results are shown in Tables 8 and 9 , respectively.

As shown in Table 9, the UIGM-RCC achieved a small deviation between the prediction values and the measured values. The mean relative error was only $1.11 \%$, far below the $8.71 \%$ of the UIGM. Figure 5 compares the box girder deformation predicted by the two models. Note that the absolute deviation of predicted values from the measured values is magnified 5 times.

Table 10 shows the 8th 12th times' prediction results of the deformation obtained by UIGM-RCC. The results show that the prediction value of the measuring point $\mathrm{C} 21$ is the largest when the cable tension is drawn to the design tension 
TABLE 5: Comparison of the fitting values by the different prediction models.

\begin{tabular}{|c|c|c|c|c|c|c|}
\hline \multirow{2}{*}{$\begin{array}{l}\text { Tensioning } \\
\text { phase }\end{array}$} & \multirow{2}{*}{$\begin{array}{l}\text { Tensioning } \\
\text { force/kN }\end{array}$} & \multirow{2}{*}{$\begin{array}{c}\text { Measured } \\
\text { values } / \mathrm{mm}\end{array}$} & \multicolumn{2}{|c|}{ UIGM } & \multicolumn{2}{|c|}{ UIGM-RCC } \\
\hline & & & Fitting values $/ \mathrm{mm}$ & Relative error/\% & Fitting values $/ \mathrm{mm}$ & Relative errors/\% \\
\hline 1 & 630 & 25.30 & 25.3000 & 0.0000 & 25.3000 & 0.0000 \\
\hline 2 & 1,050 & 31.33 & 32.4076 & -3.4394 & 30.0380 & 4.1238 \\
\hline 3 & 1,155 & 33.27 & 34.4138 & -3.4380 & 32.1588 & 3.3400 \\
\hline 4 & 1,365 & 37.15 & 35.6871 & 3.9377 & 37.2764 & -0.3404 \\
\hline 5 & 1,575 & 42.78 & 37.4548 & 12.4478 & 43.0448 & -0.6189 \\
\hline 6 & 1,785 & 45.18 & 39.3101 & 12.9923 & 44.9645 & 0.4769 \\
\hline
\end{tabular}

TABLE 6: Comparison of the predicted values by the different prediction models.

\begin{tabular}{lccc}
\hline $\begin{array}{l}\text { Tensioning } \\
\text { phase }\end{array}$ & $\begin{array}{c}\text { Tensioning } \\
\text { force/kN }\end{array}$ & \multicolumn{2}{c}{ Predicted values/mm } \\
\hline 7 & 1,890 & 40.7586 & 47.1241 \\
8 & 2,100 & 41.7640 & 48.1295 \\
9 & 2,205 & 42.2790 & 48.6445 \\
10 & 2,310 & 42.8025 & 49.1680 \\
11 & 2,415 & 43.3345 & 49.7000 \\
12 & 2,520 & 43.8754 & 50.2409 \\
\hline
\end{tabular}

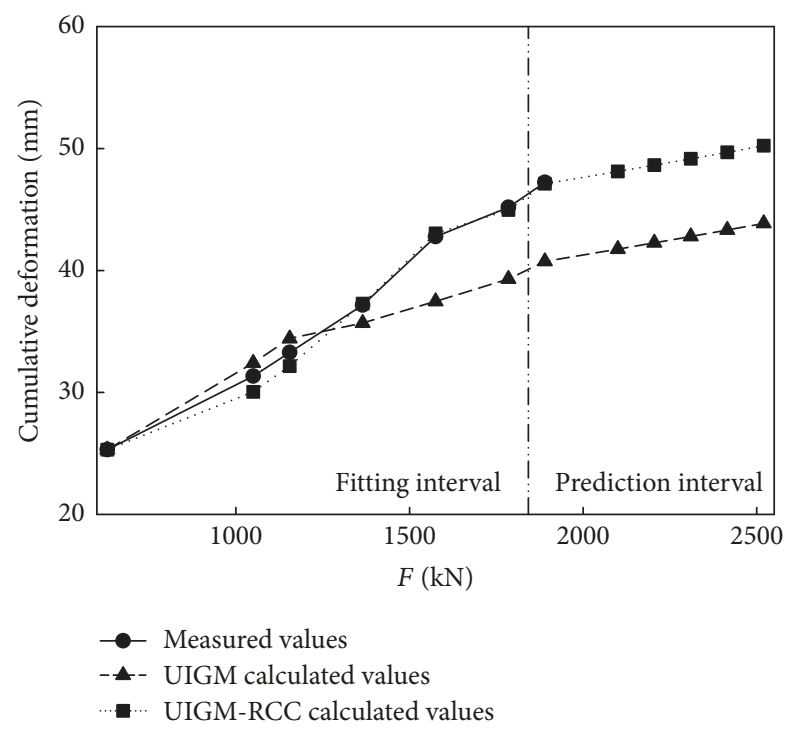

FIgURE 4: Comparison of the different model results.

value of the bridge, and its value is $48.1295 \mathrm{~mm}$. When the cable tension is drawn to the 1.2 times' design tension value of the bridge, the measuring point C21 is raised by $3.0109 \mathrm{~mm}$ compared with the span in the 7th tensioning phase, and the prediction deformation is over $50 \mathrm{~mm}$.

In addition, the UIGM-RCC and the UIGM were also applied to calculate the settlements of the building in literatures $[11,12]$ in the 9th and 10th phases according to the measured data of the first eight phases. Tables 11 and 12 compare the fitting, predicted results, and relative error of UIGM: literature [11], literature [12], and our model. Through

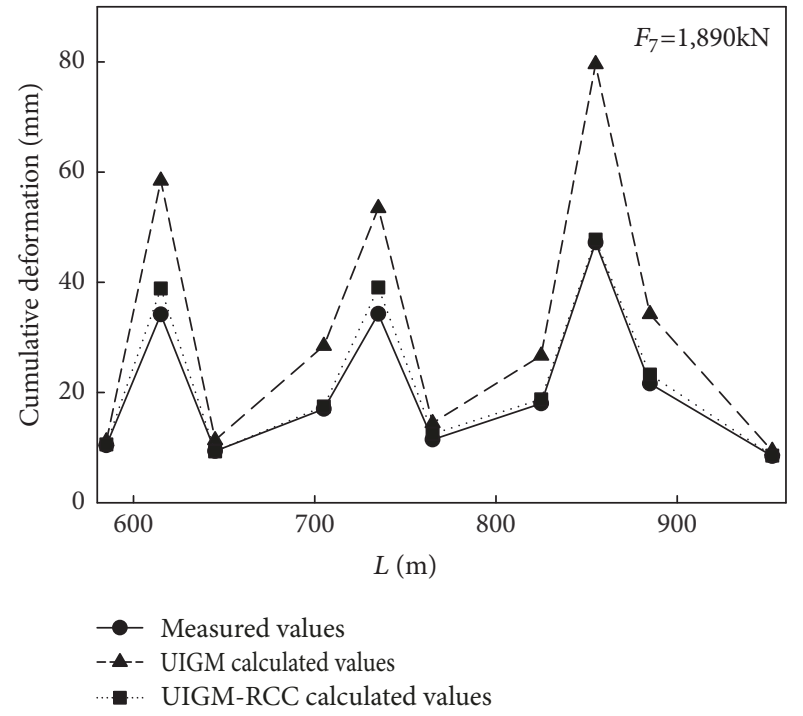

Figure 5: Prediction results of measuring points.

the comparison of results, it is learned that the UIGM-RCC has much higher prediction accuracy.

Note that the absolute deviation of calculated values from the measured values is magnified 3 times. In Figure 6, it can be seen that the results of the UIGM-RCC agree well with the measured values.

According to the measured data of the first eight phases, the UIGM-RCC is used to predict the settlement in the 160th 210th days in this paper, as shown in Table 13. The results show that the settlement is over $5 \mathrm{~mm}$ in the 174th day and the settlement is $5.6431 \mathrm{~mm}$ in the 210th day.

\section{Conclusion}

The monitoring and prediction of box girder deformation are essential to SCS-enhanced PSC continuous box girder bridges. The effective and timely prediction can guarantee the smoothness and intelligent control of tensioning. However, the box girder deformation features periodicity and random fluctuations under the joint action of environmental and anthropic factors, making it difficult to predict the deformation with common models.

The UIGM can partially overcome the difficulty in deformation prediction. However, this model faces a large 
TABLE 7: The measured values of $\mathrm{C} 14 \sim \mathrm{C} 23$ measuring points.

\begin{tabular}{lcccccccc}
\hline \multirow{2}{*}{ Measuring points } & \multirow{2}{*}{$\mathrm{L}$} & \multicolumn{5}{c}{ Measured values $/ \mathrm{mm}$} \\
& & $630 \mathrm{kN}$ & $1,050 \mathrm{kN}$ & $1,155 \mathrm{kN}$ & $1,365 \mathrm{kN}$ & $1,575 \mathrm{kN}$ & $1,785 \mathrm{kN}$ & $1,890 \mathrm{kN}$ \\
\hline C14 & 585.00 & 7.61 & 9.47 & 9.82 & 9.99 & 10.50 & 10.38 \\
C15 & 615.00 & 18.98 & 23.55 & 24.76 & 27.17 & 30.49 & 32.11 \\
C16 & 645.00 & 7.03 & 7.42 & 8.16 & 8.53 & 9.06 & 9.25 \\
C17 & 705.00 & 8.04 & 12.30 & 12.64 & 13.33 & 14.02 & 16.45 \\
C18 & 735.00 & 16.48 & 24.67 & 25.34 & 28.77 & 31.48 & 33.20 \\
C19 & 765.00 & 4.18 & 6.01 & 8.05 & 9.68 & 10.03 & 11.45 \\
C20 & 825.00 & 11.92 & 14.90 & 15.06 & 15.37 & 16.73 & 17.88 \\
C21 & 855.00 & 25.30 & 31.33 & 33.27 & 37.15 & 42.78 & 45.18 \\
C22 & 885.00 & 11.05 & 15.81 & 16.29 & 17.88 & 19.45 & 18.45 \\
C23 & 952.50 & 6.09 & 7.14 & 7.83 & 8.06 & 8.24 & 47.25 \\
\hline
\end{tabular}

TABLE 8: Optimal parameters of the different measuring points.

\begin{tabular}{|c|c|c|c|c|c|c|c|}
\hline Measuring points & $\xi$ & $T / \mathrm{s}$ & $m$ & Measuring points & $\xi$ & $T / \mathrm{s}$ & $m$ \\
\hline $\mathrm{C} 14$ & 0.35 & 204 & 7 & $\mathrm{C} 19$ & 0.33 & 204 & 7 \\
\hline $\mathrm{C} 15$ & 0.17 & 114 & 10 & $\mathrm{C} 20$ & 0.17 & 114 & 14 \\
\hline $\mathrm{C} 16$ & 0.33 & 204 & 7 & $\mathrm{C} 21$ & 0.17 & 114 & 10 \\
\hline $\mathrm{C} 17$ & 0.26 & 107 & 7 & $\mathrm{C} 22$ & 0.17 & 114 & 12 \\
\hline $\mathrm{C} 18$ & 0.35 & 203 & 7 & $\mathrm{C} 23$ & 0.07 & 203 & 7 \\
\hline
\end{tabular}

TABle 9: Prediction values of C14 C23 measuring points.

\begin{tabular}{|c|c|c|c|c|c|c|}
\hline \multirow{2}{*}{ Measuring points } & \multirow{2}{*}{$L / \mathrm{m}$} & \multirow{2}{*}{ Measured values $/ \mathrm{mm}$} & \multicolumn{2}{|c|}{ UIGM } & \multicolumn{2}{|c|}{ UIGM-RCC } \\
\hline & & & Predicted values $/ \mathrm{mm}$ & Relative error/\% & Predicted values/mm & Relative error $/ \%$ \\
\hline $\mathrm{C} 14$ & 585.00 & 10.41 & 10.2650 & 1.3929 & 10.3759 & 0.3276 \\
\hline $\mathrm{C} 15$ & 615.00 & 34.15 & 29.2886 & 14.2354 & 33.2063 & 2.7634 \\
\hline $\mathrm{C} 16$ & 645.00 & 9.35 & 8.9535 & 4.2406 & 9.3561 & -0.0652 \\
\hline $\mathrm{C} 17$ & 705.00 & 17.01 & 14.7196 & 13.4650 & 16.9213 & 0.5215 \\
\hline $\mathrm{C} 18$ & 735.00 & 34.25 & 30.4025 & 11.2336 & 33.2873 & 2.8108 \\
\hline $\mathrm{C} 19$ & 765.00 & 11.45 & 10.8515 & 5.2271 & 11.2477 & 1.7668 \\
\hline $\mathrm{C} 20$ & 825.00 & 18.01 & 16.2766 & 9.6247 & 17.8585 & 0.8412 \\
\hline $\mathrm{C} 21$ & 855.00 & 47.23 & 40.7586 & 13.7019 & 47.1241 & 0.2242 \\
\hline $\mathrm{C} 22$ & 885.00 & 21.60 & 19.0744 & 11.6926 & 21.2667 & 1.5431 \\
\hline $\mathrm{C} 23$ & 952.50 & 8.45 & 8.2588 & 2.2627 & 8.4285 & 0.2544 \\
\hline
\end{tabular}

TABLE 10: Prediction results of C14 C23 measuring points.

\begin{tabular}{|c|c|c|c|c|c|}
\hline \multirow{2}{*}{ Measuring points } & \multicolumn{5}{|c|}{ Prediction results $/ \mathrm{mm}$} \\
\hline & $2,100 \mathrm{kN}$ & $2,205 \mathrm{kN}$ & $2,310 \mathrm{kN}$ & $2,415 \mathrm{kN}$ & $2,520 \mathrm{kN}$ \\
\hline $\mathrm{C} 14$ & 10.4508 & 10.4885 & 10.5264 & 10.5645 & 10.6027 \\
\hline $\mathrm{C} 15$ & 33.8028 & 34.1071 & 34.4155 & 34.7281 & 35.0449 \\
\hline $\mathrm{C} 16$ & 9.5084 & 9.5859 & 9.6642 & 9.7434 & 9.8236 \\
\hline $\mathrm{C} 17$ & 16.5406 & 16.6357 & 16.7317 & 16.8284 & 16.9261 \\
\hline $\mathrm{C} 18$ & 33.8811 & 34.1838 & 34.4904 & 34.8010 & 35.1156 \\
\hline $\mathrm{C} 19$ & 11.8436 & 12.1578 & 12.4834 & 12.8208 & 13.1706 \\
\hline $\mathrm{C} 20$ & 17.9959 & 18.0653 & 18.1350 & 18.2051 & 18.2756 \\
\hline $\mathrm{C} 21$ & 48.1295 & 48.6445 & 49.1680 & 49.7000 & 50.2409 \\
\hline $\mathrm{C} 22$ & 21.6033 & 21.7746 & 21.9479 & 22.1232 & 22.3005 \\
\hline $\mathrm{C} 23$ & 8.5352 & 8.5892 & 8.6437 & 8.6986 & 8.7540 \\
\hline
\end{tabular}




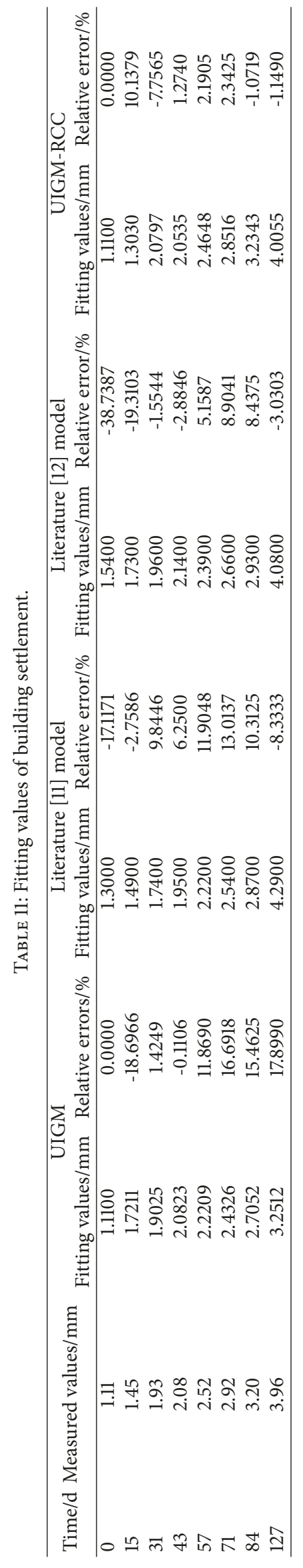


TABLE 12: Predicted values of building settlements.

\begin{tabular}{cccccccccc}
\hline \multirow{2}{*}{ Time/d } & $\begin{array}{c}\text { Measured } \\
\text { values/mm }\end{array}$ & $\begin{array}{c}\text { UIGM } \\
\text { Predicted } \\
\text { values/mm }\end{array}$ & $\begin{array}{c}\text { Relative } \\
\text { error/\% }\end{array}$ & $\begin{array}{c}\text { Literature [11] model } \\
\text { Predicted } \\
\text { values/mm }\end{array}$ & $\begin{array}{c}\text { Relative } \\
\text { error/\% }\end{array}$ & $\begin{array}{c}\text { Literature [12] model } \\
\text { Predicted } \\
\text { values/mm }\end{array}$ & $\begin{array}{c}\text { Relative } \\
\text { error/\% }\end{array}$ & $\begin{array}{c}\text { Predicted } \\
\text { values/mm }\end{array}$ & $\begin{array}{c}\text { Relative } \\
\text { error/\% }\end{array}$ \\
\hline 140 & 4.38 & 3.8847 & 11.3082 & 4.8500 & -10.7306 & 4.5000 & -2.7397 & 4.4436 & -1.4521 \\
154 & 4.68 & 4.0684 & 13.0684 & 5.5400 & -18.3761 & 5.0100 & -7.0513 & 4.5335 & 3.1303 \\
\hline
\end{tabular}

TABLE 13: Prediction results of the 160th 210th days by UIGM-RCC.

\begin{tabular}{lc}
\hline Time/d & Predicted values/mm \\
\hline 160 & 4.8577 \\
174 & 5.0603 \\
185 & 5.2285 \\
198 & 5.4383 \\
210 & 5.6431 \\
\hline
\end{tabular}

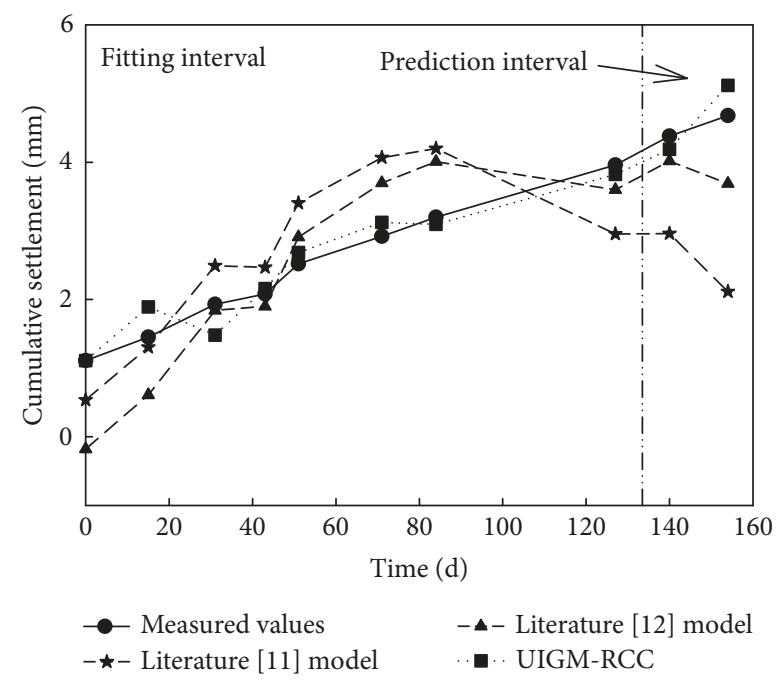

FIGURE 6: Comparison of predicted results by the different models.

deviation between the prediction value and the measured value (mean relative error: $8.71 \%$ ). In light of this, the prediction results of the UIGM were firstly modified by the SPSFRC and then corrected by the Markov chain. After the two corrections, the mean relative error was reduced to $1.11 \%$. In this way, the author created a new method for long-term deformation prediction of SCS-enhanced box girders. The proposed model was applied to predict the settlement of a building. The mean relative error of the prediction results was only $2.29 \%$, far lower than that of the UIGM and other models. This further validates the prediction accuracy of the UIGM-RCC and expands the application scope of the model.

\section{Data Availability}

The data used to support the findings of this study are available from the corresponding author upon request.

\section{Conflicts of Interest}

The authors declare that there are no conflicts of interest regarding the publication of the paper.

\section{Acknowledgments}

This work is supported by the National Natural Science Foundation of China (no. 11372165).

\section{References}

[1] I. N. Robertson, "Prediction of vertical deflections for a longspan prestressed concrete bridge structure," Engineering Structures, vol. 27, no. 12, pp. 1820-1827, 2005.

[2] N. Bagge, J. Nilimaa, and L. Elfgren, "In-situ methods to determine residual prestress forces in concrete bridges," Engineering Structures, vol. 135, pp. 41-52, 2017.

[3] G.-N. Xu, Y.-Z. Wang, S.-M. Wang, and L.-Y. Wang, "Key construction techniques for strengthening of main girder of Dongming Huanghe River Highway Bridge," Bridge Construction, vol. 47, no. 5, pp. 101-106, 2017.

[4] Z. P. Bažant, Q. Yu, and G.-H. Li, "Excessive long-time deflections of prestressed box girders. I: record-span Bridge in Palau and other paradigms," Journal of Structural Engineering, vol. 138, no. 6, pp. 676-686, 2012.

[5] H. Sousa, J. Bento, and J. Figueiras, "Construction assessment and long-term prediction of prestressed concrete bridges based on monitoring data," Engineering Structures, vol. 52, pp. 26-37, 2013.

[6] Z. Tadesse, K. A. Patel, S. Chaudhary, and A. K. Nagpal, "Neural networks for prediction of deflection in composite bridges," Journal of Constructional Steel Research, vol. 68, no. 1, pp. 138149, 2012.

[7] M. Hosseini and H. Abbas, "Neural network approach for prediction of deflection of clamped beams struck by a mass," Thin-Walled Structures, vol. 60, pp. 222-228, 2012.

[8] A. Bezuglov and G. Comert, "Short-term freeway traffic parameter prediction: Application of grey system theory models," Expert Systems with Applications, vol. 62, pp. 284-292, 2016.

[9] S. Ene and N. Öztürk, "Grey modelling based forecasting system for return flow of end-of-life vehicles," Technological Forecasting \& Social Change, vol. 115, pp. 155-166, 2017.

[10] F. Shaikh, Q. Ji, P. H. Shaikh, N. H. Mirjat, and M. A. Uqaili, "Forecasting China's natural gas demand based on optimised nonlinear grey models," Energy, vol. 140, pp. 941-951, 2017.

[11] B. Li and J. Zhu, "Application of unequal interval grey model in analysis of settlement data," Science of Surveying and Mapping, vol. 32, no. 4, pp. 52-55, 2007. 
[12] Q. Chi, S. Zhou, and F. Wang, "Re-optimization of nonequilditant gray model," Journal of Liaoning Technical University (Natural Science Edition), vol. 36, no. 5, pp. 523-527, 2017.

[13] D.-M. Zhang, J. Chen, H.-F. He, and X.-H. Zhang, "Unequal interval grey model based on dynamic correction of timedistance weight," Chinese Journal of Geotechnical Engineering, vol. 34, no. 6, pp. 1137-1141, 2012.

[14] K.-G. Li, J. Xu, and G.-Y. Huang, "Prediction for slope displacment based on unequal interval $\operatorname{GM}(1,1)$ model," Chinese Journal of Underground Space and Engineering, vol. 2, no. 6, pp. 988-992, 2006.

[15] Y. Guo and J.-M. Gao, "Track irregularity evolution prediction for high speed railways in frozen ground region based on GM(1, 1) power model," Journal of Railway Science and Engineering, vol. 13, no. 5, pp. 791-799, 2016.

[16] Q. Yang, Y.-F. Yang, Z.-X. Feng, and X.-W. Zhao, "Prediction method for passenger volume of city public transit based on grey theory and Markov model," China Journal of Highway and Transport, vol. 26, no. 6, pp. 169-175, 2013.

[17] X.-R. Li, H.-L. Chen, H. Leng, and G.-M. Chen, "Mid-long term load forecasting model with fourier series and markov theory residual error correction," Journal of Hunan University Natural Sciences, vol. 43, no. 10, pp. 62-69, 2016. 


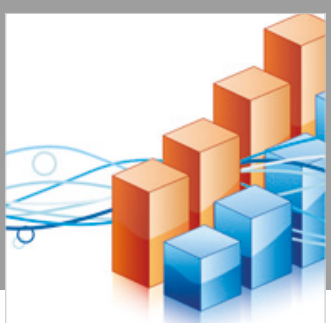

Advances in

Operations Research

\section{-n-m}
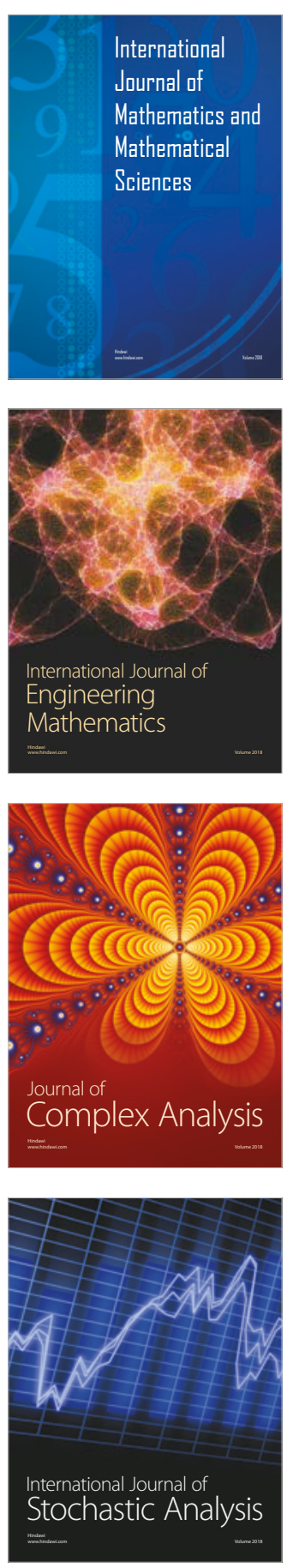
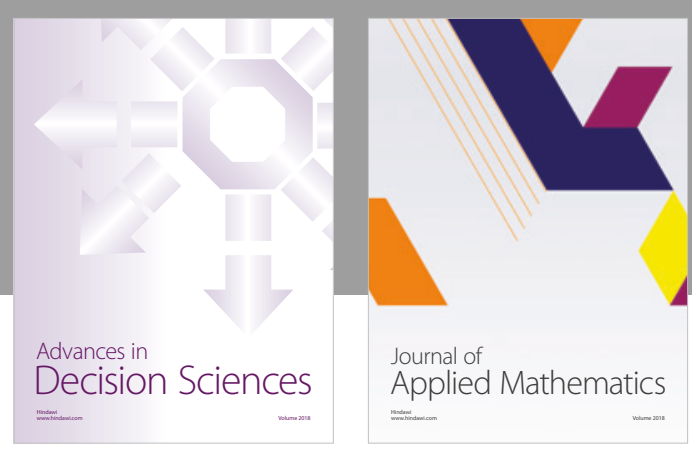

Journal of

Applied Mathematics
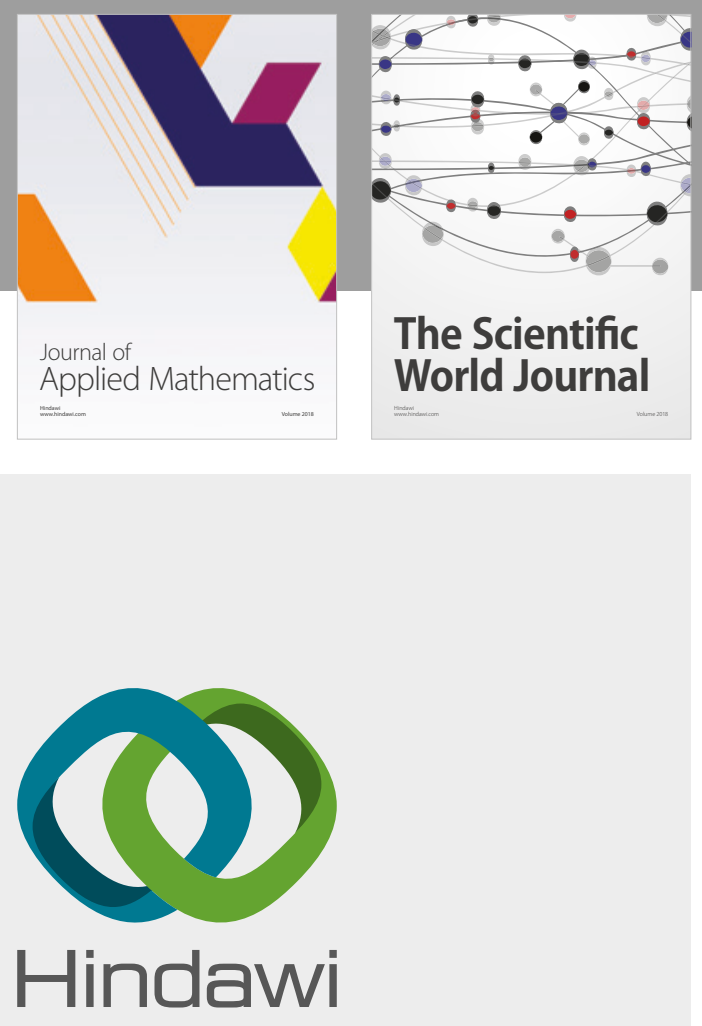

Submit your manuscripts at

www.hindawi.com

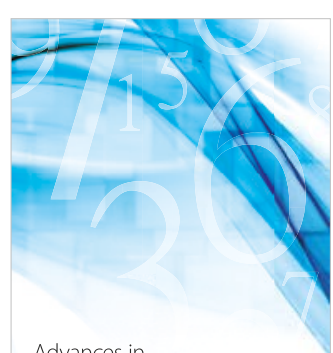

Advances in
Numerical Analysis
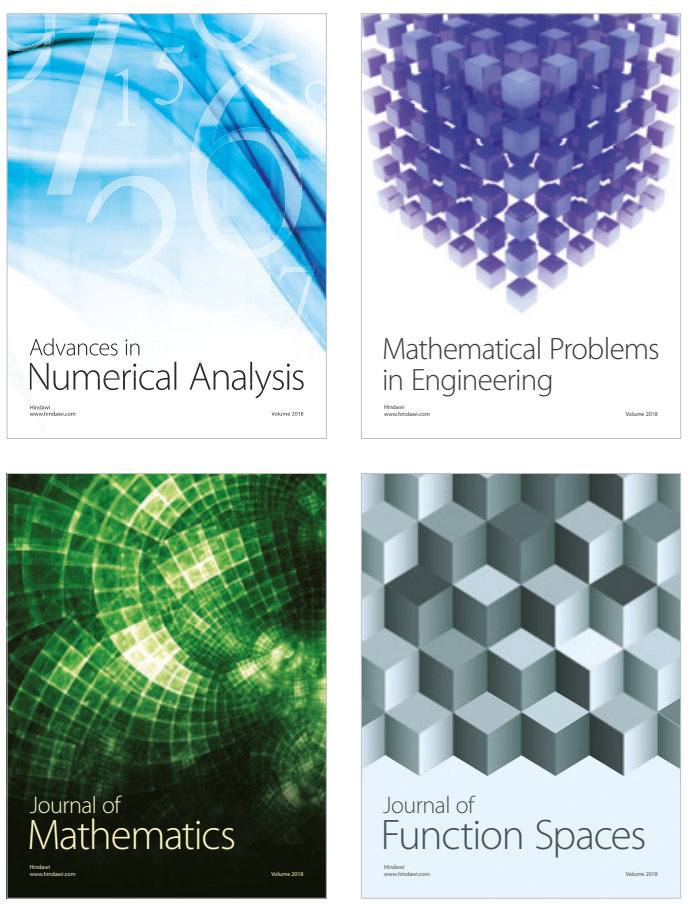

Mathematical Problems in Engineering

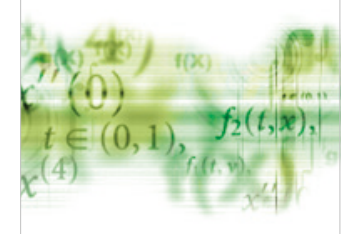

International Journal of

Differential Equations

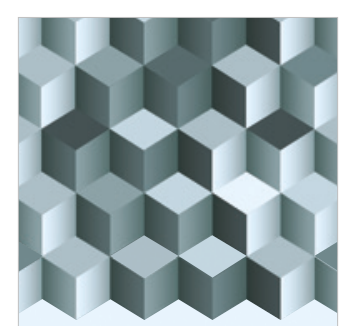

Journal of

Function Spaces

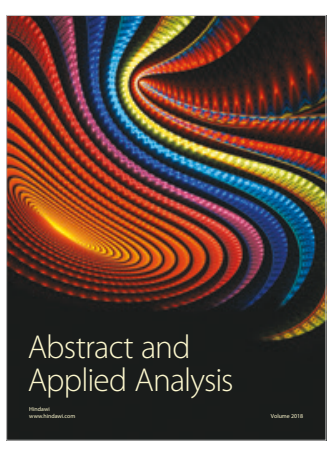

The Scientific

World Journal

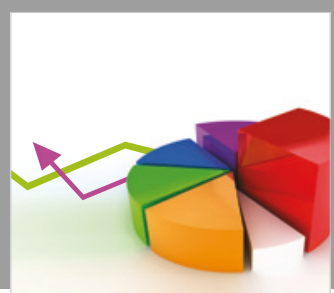

Journal of

Probability and Statistics
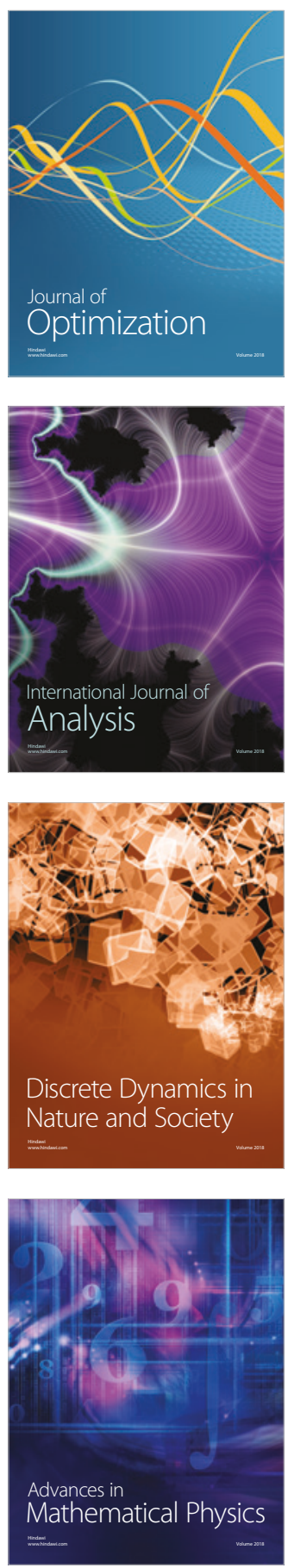